\title{
Investigating the potential impact of trophy hunting of wild ungulates on snow leopard Panthera uncia conservation in Tajikistan
}

\author{
Shannon M. KaChel, Kyle P. McCarthy \\ Thomas M. MCCARthy and Nuzar Oshurmamadov
}

\begin{abstract}
Declining availability of prey is potentially a major factor limiting snow leopard Panthera uncia populations in Tajikistan and neighbouring states. Conservation initiatives to develop community-based trophy hunting programmes for ibex Capra sibirica and argali Ovis ammon polii aim to provide financial incentives for communities to limit poaching of wild ungulates. Such programmes could help to reverse local declines in ibex and argali populations, and consequently snow leopard populations, while simultaneously improving the economic status of local people. However, in practice the desired effect may not materialize. To investigate the premise, we estimated the population density of the snow leopard, using a spatial capture-recapture model based on camera trapping in two study areas (each c. 1,00o $\mathrm{km}^{2}$ ) in the Tajik Pamirs: a wellmanaged trophy hunting concession and an otherwise similar area where grazing and poaching are unmanaged. We used distance-truncated counts to assess relative densities of wild and domestic ungulates between sites, and faecal analyses to compare the dietary habits of snow leopards. Our data were limited in scope but suggested that the density of snow leopards and the relative density of wild and domestic ungulates may have been greater in the hunting concession, where wild ungulates accounted for a greater proportion of prey items. Our results provide preliminary evidence that trophy hunting of ungulates may be a viable tool for achieving snow leopard conservation goals; however, we conclude that further investigation is necessary to adequately address the question.
\end{abstract}

Keywords Community-based conservation, diet, food habits, livestock, poaching, snow leopard, spatial capturerecapture, trophy hunting

\footnotetext{
Shannon M. KaChel ${ }^{*}$ and Kyle P. McCarthy (Corresponding author) Department of Entomology and Wildlife Ecology, University of Delaware, 250 Townsend Hall, Newark, Delaware 19716, USA. E-mail mccarthy@udel.edu

Thomas M. McCarthy and Nuzar Oshurmamadov $\dagger$ Panthera Snow Leopard Program, New York, USA

${ }^{*}$ Also at: School of Environmental and Forest Sciences, University of Washington, Box 352100, Seattle, WA 98195, USA

$\dagger$ Also at: Department of Biology, Khorog State University, Khorog, GBAO, Tajikistan

Received 15 June 2015. Revision requested 30 October 2015.

Accepted 15 February 2016. First published online 4 October 2016.
}

\section{Introduction}

$\mathrm{T}$ he Endangered snow leopard Panthera uncia has been afforded protection under local and international law, yet global population trends remain unclear (Jackson et al., 2008). The species faces numerous direct threats throughout its range, including poaching and persecution in response to livestock depredation. However, in many parts of its range the primary threat to the species' persistence may be indirect: the widespread decline of wild ungulate populations upon which it relies for food (McCarthy \& Chapron, 2003; Jackson et al., 2008). Declines in wild prey are primarily a result of illegal and unsustainable hunting, and competition with livestock (McCarthy \& Chapron, 2003; Schaller \& Kang, 2008; Berger et al., 2013).

Poaching is prevalent in the Pamir Mountains of Tajikistan, in the absence of management and enforcement efforts, and may be the main limitation for wild ungulates there (Schaller \& Kang, 2008; Michel \& Muratov, 2010). Illegal hunting is so pervasive that it may be altering ungulate behavioural and spatial responses to human proximity, thus reducing the availability of functional habitat (Rosen, 2012). Overgrazing by livestock may compound the effects of poaching on wild ungulate populations, further reducing overwinter carrying capacity (Rosen, 2012).

Community-based trophy hunting is one tool that could potentially reverse snow leopard declines associated with declines in wild prey populations (Rosen, 2012). Theoretically, with adequate revenue-sharing and transparency on the part of operators and government agencies, communitybased trophy hunting programmes can improve the availability of food resources for the snow leopard through direct economic incentives that encourage whole communities to protect and manage wild ungulate populations at levels that can sustain trophy hunting as well as predation by snow leopards. However, an economic incentive to conserve ungulates may exacerbate the persecution of snow leopards if people perceive them as a threat to their own economic interests (Hussain, 2003); i.e. greater protection for prey is not necessarily beneficial to predators.

In Tajikistan private trophy hunting operations have already proven their market potential; the government received c. USD 770,00o from the sale of permits for 51 legally harvested argali Ovis ammon polii in the 2010-2011 hunting season (Rosen, 2012). However, the ecological impact on 
ungulates and snow leopards is uncertain. Large-scale surveys of ibex Capra sibirica and argali in the region suggest that the largest local populations of these species are those protected by trophy hunting concessionaires aiming for longterm population viability and profitability (Schaller \& Kang, 2008; Michel \& Muratov, 2010). The persistence of high numbers of wild ungulates under traditional, communityimposed hunting regulatory systems in the Afghan Wakhan (Moheb et al., 2012) implies that well-managed hunting systems are a viable contextual element of local culture and are potentially more beneficial to wild ungulate populations than outright hunting bans. In Pakistan a community-based trophy hunting programme that limited harvesting of urial Ovis vignei and markhor Capra falconeri to no more than five individuals per year led to strict community-enforced bans on poaching, and populations of the species increased from 1,200 to 3,100 urial and 700 to 2,500 markhor between 1994 and 2005 (Frisina \& Tareen, 2009).

Greater abundance of wild ungulates, fostered by community-based trophy hunting programmes, could theoretically lead to numerical and behavioural responses from snow leopards. Where wild ungulates are present in sufficient numbers they account for $45-98 \%$ of the snow leopard's diet (Anwar et al., 2011; Shehzad et al., 2012; Jumabay-Uulu et al., 2013). In the absence of robust populations of wild ungulates, domestic livestock and small mammals may account for up to $70 \%$ of the snow leopard's diet (Bagchi \& Mishra, 2006; Anwar et al., 2011; Lyngdoh et al., 2014). Given the relatively limited breadth of the snow leopard's food habits, observed differences in diet between managed and unmanaged areas could suggest that the availability of wild prey is limiting snow leopards, although it would not rule out other hypotheses.

If the conceptual links between trophy hunting and conservation goals do not hold in reality then the anticipated direct benefits to local communities and wild ungulates, along with the indirect benefits to snow leopards, may never materialize. We investigated how trophy hunting management for wild ungulates in the eastern Pamir Mountains might affect snow leopards. We estimated snow leopard density and the relative density of ungulates at two sites in the Tajik Pamirs that were representative of the extremes of wild ungulate management in the region: a well-managed, private trophy hunting concession and an unregulated area where poaching was prevalent. We used faecal analysis of genetically verified samples to explore differences in dietary habits of snow leopards between the sites. We compared all metrics between the two sites to investigate how prey availability may affect snow leopards in the region.

\section{Study area}

Our research was conducted at two study sites (each c. $1,000 \mathrm{~km}^{2}$ ) in the eastern Pamir Mountains of

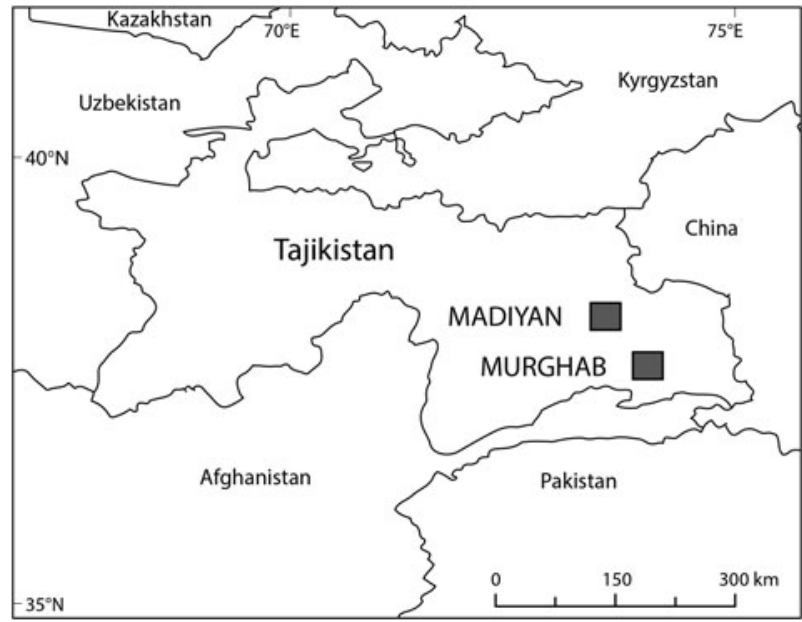

FIG. 1 Location of the Madiyan unmanaged area and the Murghab Hunting Concession in the Pamir Mountains of Tajikistan.

Tajikistan (Fig. 1) during June-September 2012. We compared a profitably managed, private trophy hunting concession (for argali and ibex) operated by the Murghab Hunting Company with the Madiyan unmanaged area, where we presume ungulate poaching is more prevalent. Terrain at both sites alternates between broad, high river valleys and steep mountain ranges, at c. 3,600-5,500 m elevation. Plant communities are characterized by xerophytic alpine grasses and forbs and slow-growing dwarf shrub communities. In addition to ibex and argali, both sites support marmots Marmota longicauda, hare Lepus tolai, wolves Canis lupus, red foxes Vulpes vulpes, brown bears Ursus arctos, and Eurasian lynx Lynx lynx.

The Madiyan unmanaged area is characterized by the broad valleys of the Murghab and Pshart drainages, surrounded by steep terrain and dissected by numerous subdrainages. There is a permanent settlement at Madiyan village, in the Murghab drainage, which is home to c. 10 families, and there are herders' camps at c. $5 \mathrm{~km}$ intervals along the lengths of the central drainages. The town of Murghab, with a population of 4,00o people, lies c. $15 \mathrm{~km}$ beyond the eastern edge of the study area. There is no effective, formal enforcement of wildlife laws in this area, and given its proximity to the largest regional population centre, poaching pressure is presumably greater here than in the Murghab concession.

The Murghab Hunting Company concession, c. $80 \mathrm{~km}$ south-east of Madiyan, is also characterized by alternating broad valleys and steep mountains. The concession is the permanent home of c. 10 families, although summer seasonal camps are established in each of the sub-drainages and side valleys of the area. According to the Murghab Hunting Company it uses 40-50 hunting permits for argali and a similar number for ibex annually. During the autumn rut the company employs up to 20 rangers to patrol the 
concession, but only 3-5 rangers throughout the rest of the year. The company engages with potential poachers to limit poaching within the territory it controls. Tactics include confiscation of firearms and construction of mechanical obstacles that prevent vehicular access. Since 2010 the company has confiscated nearly 100 rifles from would-be poachers. Nonetheless rangers for the company report that local herders, soldiers and police poach at least 50-60 argali within the concession during a typical year. Although some local herders and other local people are employed as rangers, they do not benefit from direct revenue sharing. Surveys of ibex and argali in 2009 indicated that the concession area supported the highest regional abundance of both species (Michel \& Muratov, 2010).

\section{Methods}

At both sites we estimated the relative densities of snow leopards and ungulates, and we quantified the dietary habits of snow leopards. We expected ungulate populations in the hunting concession to be better protected from poaching, thus providing more prey to support a higher density of snow leopards.

In a separate study using the same dataset we compared the use of spatial capture-recapture models and traditional capture-recapture models with ad hoc effective trapping areas for estimating snow leopard densities (Kachel, 2014). Based on the results, we chose to use the spatial capture-recapture model described here, as the evidence suggested it was more accurate. We used the packages SPACECAP v. 1.o.6 (Gopalaswamy et al., 2012) and SCRbayes v. o.20 (Royle et al., 2014) in $R$ v. 3.1.o (R Development Core Team, 2014) to build Bayesian spatial capture-recapture models of snow leopard density based on camera-trap detections (Jackson et al., 2006; Royle et al., 2014). In June and September 2012 we operated camera traps at the hunting concession ( 37 trap stations) and unmanaged study area (34 trap stations) for a total of 2,647 and 2,222 trap nights, respectively (Figs $2 \& 3$ ). We placed cameras relative to landscape features such as ridgelines, saddles and outcrops, to maximize the chance of detecting snow leopards (Jackson et al., 2006). Two researchers independently identified individual snow leopards photographed. We excluded captures of dependent young, and adults whose identity was unclear. We defined a capture as all photographs of an individual obtained at a single camera station within a 0.5 hour period. We defined a sampling occasion as a 24 -hour period during oo.oo-23.59. Given anticipated ecological differences, we estimated density separately for each study area in SPACECAP to incorporate site-specific conditions and movements latent in the data in the modelling process. In site-specific models we used state-space grids of $0.25 \mathrm{~km}^{2}$ potential snow leopard activity centres, extending $10 \mathrm{~km}$

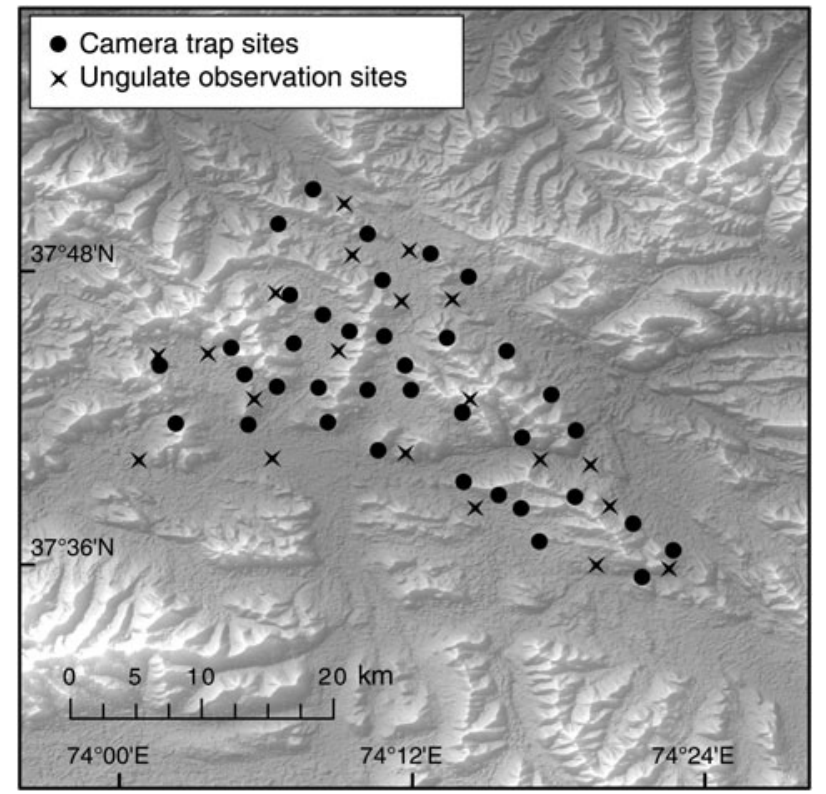

FIG. 2 Camera trap sites and ungulate survey points in the Murghab Hunting Company concession, Tajikistan (Fig. 1).

beyond the cardinal extremes of each camera-trapping grid. We evaluated the hypothesis that snow leopard density varied between the two sites, using a combined spatial capture-recapture model and a Bayesian generalized linear modelling approach, and interpreted a $95 \%$ credible interval for $\beta_{\text {DENSITY }}>$ o as indicative of a difference in snow leopard densities (Royle et al., 2014). In the combined model we defined the state-space of the model as a grid of $6.25 \mathrm{~km}^{2}$ potential snow leopard activity centres, extending $10 \mathrm{~km}$ beyond the cardinal extremes of the combined regional study area, as finer spatial resolutions were prohibitively intensive computationally without offering any enhanced understanding of the system. Using site as a covariate (Madiyan $=0$, Murghab $=1$ ) we assigned each pixel of the rectangular state-space to either the managed or unmanaged area, based on proximity to the camera traps in each study area. For each model we ran two chains of 100,000 Markov chain Monte Carlo iterations, treating the first 50,000 iterations as burn-in, with a thinning rate of 10 . We evaluated goodness-of-fit of the detection process of the model using the Bayesian P-value approach (Gelman \& Rubin, 1992; Royle et al., 2011), and evaluated Markov chain Monte Carlo convergence using the Gelman-Rubin diagnostic $\hat{R}$ (Gelman \& Rubin, 1992) in the $R$ package coda (Plummer et al., 2006).

Originally we sought to evaluate ungulate abundance using distance sampling (Buckland et al., 2001). However, the sample sizes achieved in our surveys conducted in late September and early October 2013 (we were unable to complete ungulate surveys in 2012 because of civil insecurity) were inadequate for distance sampling analysis $(n=c .60$; Buckland et al., 2001). Consequently, we report relative 


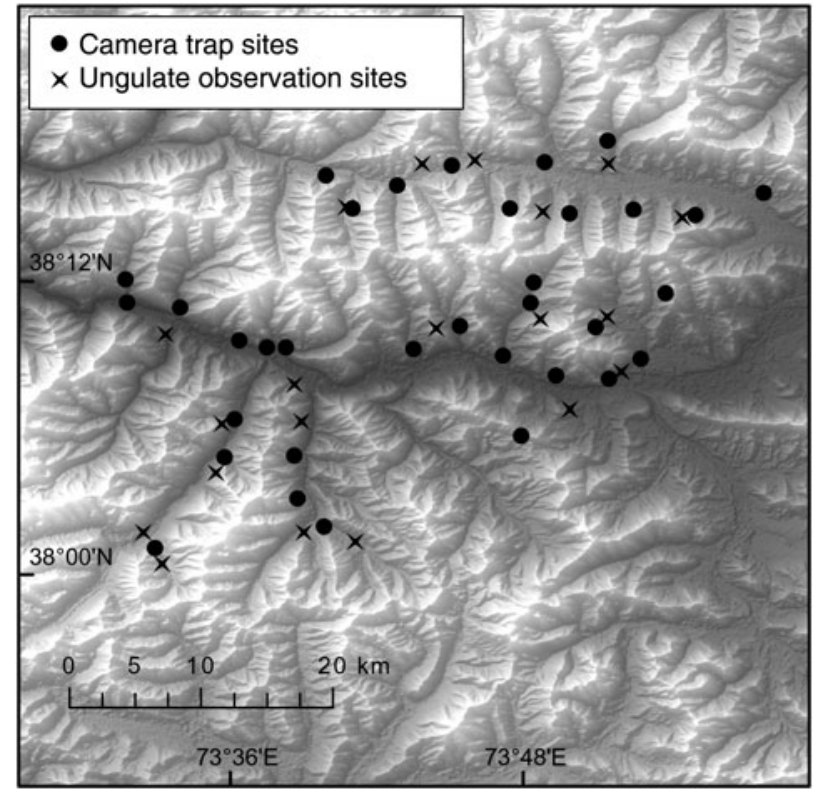

FIG. 3 Camera trap sites and ungulate survey points in the Madiyan unmanaged area, Tajikistan (Fig. 1).

densities between the two study areas. We subdivided each area into a grid of $16 \mathrm{~km}^{2}$ cells, of which we surveyed 20 , selected at random. Within each survey cell we selected locations that afforded views of large areas, from which we conducted 90-minute surveys during the morning or late afternoon, when ungulates were more likely to be active. We recorded location, group size, sex, age, and behaviour of all wild and domestic ungulates, using $1: 50,000$ scale aerial photographs, global positioning system units, compasses, binoculars and spotting scopes. Using ArcGIS v. 10.1 (ESRI, Redlands, USA) we estimated the visible area from each survey point to a radius of $3 \mathrm{~km}$. Given our inability to model detection we assumed that detection was approximately equal in each area, based on similar terrain and survey protocols, and therefore we compared the sites using the mean species-specific relative densities, calculated as the mean density within a radius of $3 \mathrm{~km}$.

We collected putative snow leopard faecal samples opportunistically while deploying camera traps. We preserved a portion of each sample in $10 \mathrm{ml}$ vials with $6 \mathrm{ml}$ of silica desiccant, and genetic analyses were conducted at the Center for Conservation Genetics at the American Museum of Natural History to confirm species identity. We air dried the remaining portions and stored them in sealable plastic bags for later diet analysis. Guard hairs are the only reliably identifiable structures present in snow leopard faeces that retain unique species-specific morphological characteristics (Oli et al., 1993; Anwar et al., 2012). Using genetically confirmed snow leopard scats, we selected up to 20 guard hairs at random from each sample, from which we prepared whole mounts and cuticular scale casts for observation under $40 \times$ magnification. We were thus able to identify species based on medullar and cuticular characteristics of the hairs, following Brunner \& Coman (1974). Following Lyngdoh et al. (2014) we quantified the snow leopard's diet as the relative frequency of occurrence of prey species, and percentage biomass consumed (a metric based on gut passage rates in a similar-sized felid, Puma concolor (Ackerman et al., 1984), and the biomass consumed by adult females, reported by Nowak (1999), adjusted by $75 \%$ to account for unknown prey demographics, as suggested by Schaller, 1972). We assessed the adequacy of our scat sample size using species accumulation curves (Gotelli \& Colwell, 2001; Foster et al., 2010).

\section{Results}

We identified six individual adult snow leopards from 14 photograph-capture events at the Madiyan unmanaged area, and 14 from 61 events at the Murghab concession. None of the individuals were detected in both areas. Camera performance, measured as the mean number of days of functional operation, varied between study areas and trap sites (unmanaged area, 67.33 \pm SD 34.95 days; hunting concession, $72.03 \pm \mathrm{SD} 21.56$ days). We estimated densities of 0.74 adult snow leopards per $100 \mathrm{~km}^{2}$ (95\% credible interval $0.57-0.95$ ) in the hunting concession and 0.46 per $100 \mathrm{~km}^{2}$ (95\% CI $0.20-0.83$ ) in the unmanaged area. In the combined model the $95 \% \mathrm{CI}$ for the site covariate, $\beta_{\text {DENSITY }}$, did not overlap o, supporting the conclusion that densities were greater in the hunting concession. Convergence diagnostics were satisfactory for the parameters of all three models (all $\hat{R}<1.2$ ), and goodness-of-fit tests indicated adequate model fit (Table 1).

We observed greater point estimates for uncorrected abundance, relative density and mean group size of both wild and domestic ungulates in the trophy hunting concession than in the unmanaged area, but small sample sizes and widely dispersed non-normal data hindered our ability to discriminate statistically between the two sites (Table 2). The sum of visible area within $3 \mathrm{~km}$ of survey points was similar in both study areas $\left(186\right.$ and $185 \mathrm{~km}^{2}$ for the concession and unmanaged area, respectively; Figs 2 \& 3 ).

Of 99 scats collected in the unmanaged area, we genetically confirmed $22(22.2 \%)$ as snow leopard, compared to 36 of $93(38.7 \%)$ scats in the hunting concession. We identified seven prey species in confirmed scats (Table 3). Two scats collected in the Madiyan area contained only vegetation (Myricaria squamosa) and snow leopard hair, and we excluded them from the analysis. Species accumulation curves indicated that we detected all probable prey species in the region (Fig. 4). At both sites $20 \%$ of the scats contained multiple prey items. The frequency of occurrence and percentage biomass contribution of prey items varied between study sites for species and functional prey groups (Table 3 , Fig. 5). Wild ungulates comprised $79 \%$ of the prey biomass 
TABLE 1 Snow leopard Panthera uncia density $\left(\mathrm{D}=\right.$ individuals per $\left.100 \mathrm{~km}^{2}\right)$, and parameter estimates from camera trapping Bayesian spatial capture-recapture models for a private trophy hunting concession (Murghab) and an unmanaged site (Madiyan) in Tajikistan (Fig. 1) during June-September 2012.

\begin{tabular}{|c|c|c|c|c|c|c|}
\hline \multirow[b]{2}{*}{ Site } & \multirow[b]{2}{*}{ Bayes P-value ${ }^{1}$} & \multirow[b]{2}{*}{ Parameter $^{2}$} & \multirow[b]{2}{*}{ Mean \pm SD } & \multicolumn{2}{|c|}{ Credible interval } & \multirow[b]{2}{*}{$\hat{R}^{3}$} \\
\hline & & & & $2.5 \%$ & $97.5 \%$ & \\
\hline \multirow[t]{3}{*}{ Madiyan } & 0.5637 & $D$ & $0.46 \pm$ SD 0.20 & 0.20 & 0.83 & \\
\hline & & $\sigma$ & $5.18 \pm$ SD 1.18 & 3.18 & 7.47 & 1.06 \\
\hline & & $\lambda_{0}$ & $0.01 \pm$ SD 0.01 & 0.00 & 0.02 & 1.15 \\
\hline \multirow[t]{3}{*}{ Murghab } & 0.5467 & $D$ & $0.74 \pm \mathrm{SD} 0.11$ & 0.57 & 0.95 & \\
\hline & & $\sigma$ & $7.27 \pm \mathrm{SD} 0.70$ & 6.00 & 8.69 & 1.00 \\
\hline & & $\lambda_{0}$ & $0.01 \pm \mathrm{SD}<0.01$ & 0.01 & 0.02 & 1.06 \\
\hline Combined & 0.6144 & $\beta_{\text {DENSITY }}$ & $1.06 \pm$ SD 0.52 & 0.10 & 2.16 & 1.02 \\
\hline
\end{tabular}

${ }^{1}$ Values of $0.05-0.95$ indicate adequate fit for the detection model

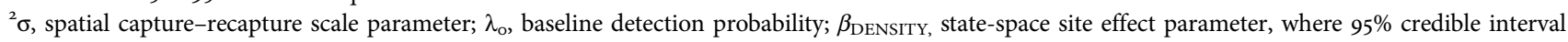
values $>0$ indicate a significant difference in density between sites

${ }^{3} \hat{R}<1.2$ indicates adequate model convergence

TABLE 2 Observed abundance and density of wild and domestic ungulates at the Murghab Hunting Concession and the Madiyan unmanaged area in Tajikistan (Fig. 1) during September and October 2013. Results are not corrected for imperfect detection, and are truncated to include only animals that were observed within $3 \mathrm{~km}$ of observers. Mean density is based on the density observed at each survey point.

\begin{tabular}{lllcccc}
\hline Species & Site & $\begin{array}{l}\text { No. of } \\
\text { groups }\end{array}$ & $\begin{array}{l}\text { Mean group } \\
\text { size }\end{array}$ & $\begin{array}{l}\text { Total no. of } \\
\text { individuals }\end{array}$ & $\begin{array}{l}\text { Mean density } \pm \text { SE } \\
\left(\text { per } 100 \mathrm{~km}^{2}\right)\end{array}$ \\
\hline Argali Ovis ammon polii & Murghab & 14 & 70 & 980 & $10.96 \pm$ SE 32.23 \\
Ibex Capra sibirica & Madiyan & 1 & 5 & 5 & $0.07 \pm$ SE 0.33 \\
& Murghab & 16 & 19.3 & 309 & $4.32 \pm$ SE 7 & 4.47 \\
Livestock & Madiyan & 11 & 15.5 & 170 & $1.95 \pm$ SE 3.18 \\
& Murghab & 18 & 196.8 & 3,594 & $62.66 \pm$ SE 88.67 & 1.62 \\
& Madiyan & 16 & 146.9 & 2,350 & $25.05 \pm$ SE 47.04 & 1.32 \\
\hline
\end{tabular}

in the Murghab concession, compared to $49 \%$ in the unmanaged area. Ibex accounted for a similar proportion of dietary biomass in both areas (47 and 44\%) but argali were more prevalent in the diet of snow leopards in the hunting concession ( 32 vs $5 \%$ ). In contrast, livestock accounted for $26 \%$ of the estimated dietary biomass in the unmanaged area but were not observed at all in the concession. Non-ungulate prey was present in a large portion of scats from both sites and accounted for a similar percentage of dietary biomass (21 and 26\%).

\section{Discussion}

Our results provide some support for the premise that snow leopards may benefit from trophy hunting of ungulates. However, small sample sizes, tenuous conceptual links, and a lack of replication across management regimes require us to view our findings as suggestive rather than conclusive, and to concede that further research is necessary to assess the conservation value of ungulate trophy hunting for snow leopards.

The two-fold differences in capture rates (0.53 vs 0.27 individual snow leopards per 100 trap nights) and total number of individuals detected, considered together with the posterior distribution of the $\beta_{\text {DENSITY }}$ parameter, all support the conclusion that snow leopard density was statistically greater in the trophy hunting concession. The emergence of a clear statistical signal despite our comparatively small camera trapping sample size further strengthens this conclusion.

Relative density estimates suggest that argali, ibex and livestock are more common in the Murghab hunting concession but our sample sizes were inadequate to draw clear conclusions. The wide dispersion of ungulate counts and parameter estimates, particularly for argali, probably reflect the clumpy distribution of herd animals across both study areas, given that both wild and domestic ungulates, particularly argali, form large herds (Michel \& Muratov, 2010, observed herds of $>1,000$ argali). We regard our results as indicative primarily of the direction, not necessarily the magnitude, of the differences between sites. They are consistent with other observations indicating a greater abundance of wild ungulates in the Murghab concession than elsewhere in the Tajik Pamirs (Schaller, 2005; Schaller \& Kang, 2008; Michel \& Muratov, 2010). Although Soviet-era population estimates are lacking or unreliable (Michel \& Muratov, 2010), anecdotal evidence suggests that unlike today, historically population levels of 

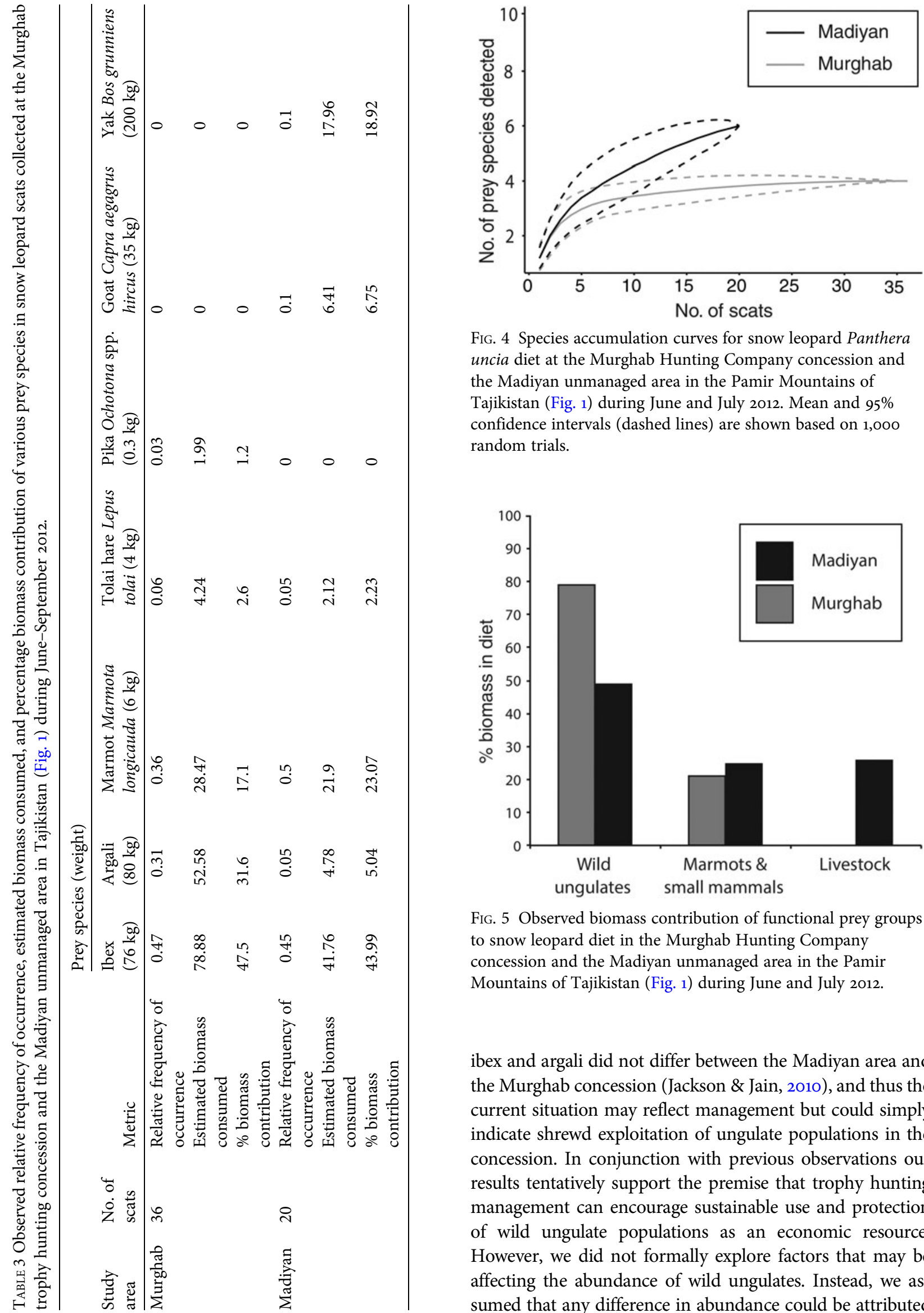

FIG. 4 Species accumulation curves for snow leopard Panthera uncia diet at the Murghab Hunting Company concession and the Madiyan unmanaged area in the Pamir Mountains of Tajikistan (Fig. 1) during June and July 2012. Mean and 95\% confidence intervals (dashed lines) are shown based on 1,00o random trials.

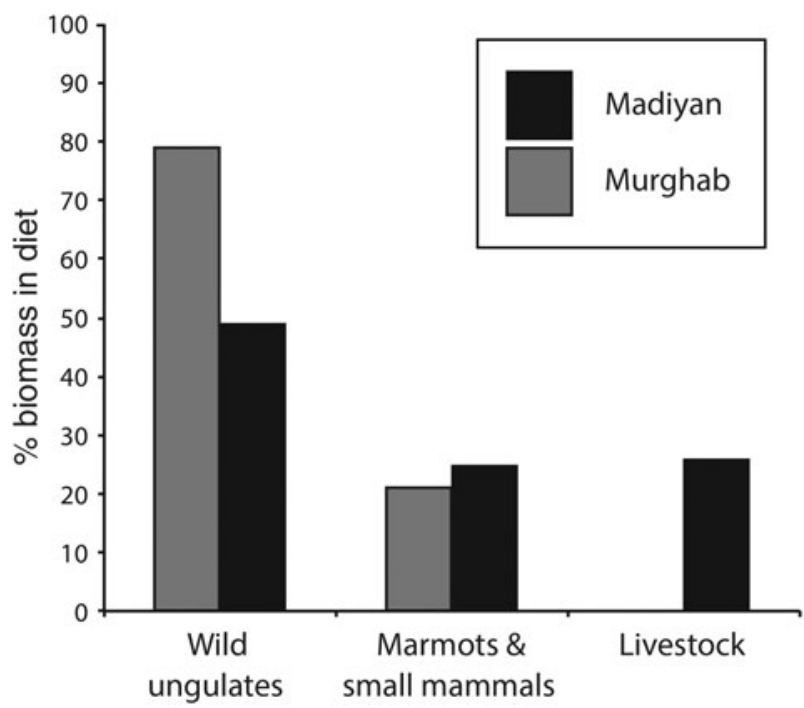

FIG. 5 Observed biomass contribution of functional prey groups to snow leopard diet in the Murghab Hunting Company concession and the Madiyan unmanaged area in the Pamir Mountains of Tajikistan (Fig. 1) during June and July 2012.

ibex and argali did not differ between the Madiyan area and the Murghab concession (Jackson \& Jain, 2010), and thus the current situation may reflect management but could simply indicate shrewd exploitation of ungulate populations in the concession. In conjunction with previous observations our results tentatively support the premise that trophy hunting management can encourage sustainable use and protection of wild ungulate populations as an economic resource. However, we did not formally explore factors that may be affecting the abundance of wild ungulates. Instead, we assumed that any difference in abundance could be attributed 
to company-run anti-poaching efforts and selective harvest regimes in the concession. We gathered anecdotal evidence that levels of human activity, including illegal hunting, were greater in the Madiyan unmanaged area, where camera traps recorded three events involving five presumed poachers armed with rifles, and four events involving 28 people engaged in fuel collection activities. In the Murghab concession, cameras detected three armed poachers, in two events, suggesting that poaching pressure is greater outside the concession and that poaching intensity may be a major threat to argali and ibex in the region.

Our observations of the snow leopard's dietary habits concur with previous observations that wild and domestic ungulates account for the majority of the species' diet (Bagchi \& Mishra, 2006; Lovari et al., 2009; Anwar et al., 2011; Shehzad et al., 2012; Lyngdoh et al., 2014). Despite substantial livestock populations in the concession we did not detect livestock consumption there. At both locations ungulates comprised $75-80 \%$ of the estimated biomass in the snow leopard's diet. In the concession that portion was accounted for entirely by wild ungulates, whereas domestic livestock accounted for more than a third of all ungulate biomass consumed at the unmanaged site. If this pattern reflects reality, snow leopards outside the concession could shift to rely upon livestock (as well as marmots and other secondary prey) for various reasons, including potentially lower wild ungulate abundance but also individual variability, livestock husbandry practices and the snow leopard's social structures. Further investigation is needed, as our data were insufficient for conclusive detection of an effect.

Although exploratory in nature and hampered by small sample sizes, our results generally confirmed our predictions: the trophy hunting concession appeared to support greater abundance of ibex and argali, and a higher density of snow leopards. In turn, snow leopards apparently relied more on wild ungulates in the concession and shifted to domestic prey elsewhere. The threats currently facing ibex and argali in the eastern Pamirs (poaching and competition with livestock) could potentially be mitigated through communitybased incentives (Frisina \& Tareen, 2009). However, linking ungulate conservation to snow leopard conservation requires additional research as well as logistical groundwork and longterm monitoring. Ungulate trophy hunting programmes could create a perverse incentive to intensify persecution of snow leopards if snow leopards are perceived as a threat to the wild ungulate resource (Hussain, 2003), and therefore care must be taken to ensure that trophy hunting programmes intended to benefit snow leopard populations indirectly do not instead harm them directly.

Our attempt to evaluate the effect of ungulate trophy hunting on snow leopards was hindered by low detection rates, small sample sizes and a lack of replication. If trophy hunting is to be used successfully as a tool for snow leopard conservation, biological, logistical and cultural considerations must all be addressed, and the implications identified. Although difficult to evaluate, the impact of ungulate trophy hunting on snow leopards and their prey nonetheless requires and merits further investigation.

\section{Acknowledgements}

This research was supported by Panthera and the University of Delaware. The Center for Conservation Genetics performed all genetic analyses. We are grateful for the valuable laboratory and field contributions made by Sarah Weiskopf, Dana Goin, Nosirsho Kimatshoev, Komil Saidov, Tolibek Gulbekov, Atobek Bekmurodi and Khalil Karimov. Rana Bayrakcismith, Tanya Rosen and Stefan Michel provided crucial logistical and analytical support.

\section{References}

Ackerman, B.B., Lindzey, F.G. \& Hemker, T.P. (1984) Cougar food habits in southern Utah. The Journal of Wildlife Management, 48 , 147-155.

Anwar, M.B., Jackson, R., Nadeem, M.S., Janečka, J.E., Hussain, S., BEG, M.A. et al. (2011) Food habits of the snow leopard Panthera uncia (Schreber, 1775) in Baltistan, Northern Pakistan. European Journal of Wildlife Research, 57, 1077-1083.

Anwar, M.B., Nadeem, M.S., Beg, M.A., Kayani, A.R. \& Munammad, G. (2012) A photographic key for the identification of mammalian hairs of prey species in snow leopard (Panthera uncia) habitats of Gilgit-Baltistan province of Pakistan. Pakistan Journal of Zoology, 44, 737-743.

BAGCHI, S. \& Mishra, C. (2006) Living with large carnivores: predation on livestock by the snow leopard (Uncia uncia). Journal of Zoology, 268, 217-224.

Berger, J., Buuveibaatar, B. \& Mishra, C. (2013) Globalization of the cashmere market and the decline of large mammals in Central Asia. Conservation Biology, 27, 679-689.

BRUnner, H. \& Coman, B. (1974) The Identification of Mammalian Hair. Inkata Press, Melbourne, Australia.

Buckland, S.T., Anderson, D.R., Burnham, K.P., LaAke, J.L., Borchers, D.L. \& Thomas, L. (2001) Introduction to Distance Sampling. Oxford University Press, Oxford, UK.

Foster, R.J., Harmsen, B.J. \& Doncaster, C.P. (2010) Sample-size effects on diet analysis from scats of jaguars and pumas. Mammalia, $74,317-321$.

Frisina, M.R. \& TAREen, S.N.A. (2009) Exploitation prevents extinction: case study of endangered Himalayan sheep and goats. In Recreational Hunting, Conservation and Rural Livelihoods: Science and Practice (eds B. Dickson, J. Hutton \& W.M. Adams), pp. 141-156. Wiley-Blackwell, Oxford, UK.

Gelman, A. \& Rubin, D.B. (1992) Inference from iterative simulation using multiple sequences. Statistical Science, 7, 457-472.

Gopalaswamy, A.M., Royle, J.A., Hines, J.E., Singh, P., Jathanna, D., Kumar, N.S. \& Karanth, K.U. (2012) Program SPACECAP: software for estimating animal density using spatially explicit capture-recapture models. Methods in Ecology and Evolution, 3 , 1067-1072.

Gotelli, N.J. \& Colwell, R.K. (2001) Quantifying biodiversity: procedures and pitfalls in the measurement and comparison of species richness. Ecology Letters, 4, 379-391. 
Hussain, S. (2003) The status of the snow leopard in Pakistan and its conflict with local farmers. Oryx, 37, 26-33.

Jackson, R. \& Jain, N. (2010) Mountain Voices and Community Actions: Local Initiatives in Biodiversity Conservation and Livelihoods in Central Asia. Snow Leopard Conservancy, Sonoma, USA.

Jackson, R., Mallon, D., McCarthy, T., Chundaway, R.A. \& Hавів, B. (2008) Panthera uncia. The IUCN Red List of Threatened Species v. 2001.2. Http://www.iucnredlist.org [accessed 27 February 2012].

Jackson, R.M., Roe, J.D., WangChuK, R. \& Hunter, D.O. (2006) Estimating snow leopard population abundance using photography and capture-recapture techniques. Wildlife Society Bulletin, 34, $772-781$.

Jumabay-Uulu, K., Wegge, P., Mishra, C. \& Sharma, K. (2013) Large carnivores and low diversity of optimal prey: a comparison of the diets of snow leopards Panthera uncia and wolves Canis lupus in Sarychat-Ertash Reserve in Kyrgyzstan. Oryx, 48, 529-535.

KACHEL, S. (2014) Evaluating the efficacy of wild ungulate trophy hunting as a tool for snow leopard conservation in the Pamir Mountains of Tajikistan. MSc thesis. University of Delaware, Newark, USA.

Lovari, S., Boesi, R., Minder, I., Mucci, N., Randi, E., Dematteis, A. \& ALE, S.B. (2009) Restoring a keystone predator may endanger a prey species in a human-altered ecosystem: the return of the snow leopard to Sagarmatha National Park. Animal Conservation, 12, 559-570.

Lyngdoh, S., Shrotriya, S., Goyal, S.P., Clements, H., Hayward, M.W. \& Haвiв, B. (2014) Prey preferences of the snow leopard (Panthera uncia): regional diet specificity holds global significance for conservation. PLoS ONE, 9(2), e88349.

McCarthy, T.M. \& Chapron, G. (2003) Snow Leopard Survival Strategy v. 2003. International Snow Leopard Trust and Snow Leopard Network, Seattle, USA.

Michel, S. \& Muratov, R. (2010) Working Report of the Project Survey on Marco Polo Sheep and other Mammal Species in the Eastern Pamirs (Republic of Tajikistan, GBAO). Unpublished report. Academy of Sciences of Tajikistan. Khorog, Tajikistan.

Moheb, Z., Mostafawi, N., Noori, H., Rajabi, A.M., Ali, H. \& IsmaiLy, S. (2012) Urial Survey in the Hindu Kush Range in the Wakhan Corridor, Badakhshan Province, Afghanistan. Wildlife Conservation Society, Kabul, Afghanistan.

Nowak, R.M. (1999) Walker's Mammals of the World, 6th edition. The Johns Hopkins University Press, Baltimore, USA.
Oli, M.K., Taylor, I.R. \& Rogers, D.M.E. (1993) Diet of the snow leopard (Panthera uncia) in the Annapurna Conservation Area, Nepal. Journal of Zoology, 231, 365-370.

Plummer, M., Best, N., Cowles, K. \& Vines, K. (2006) CODA: convergence diagnosis and output analysis for MCMC. R News, 6 , 7-11.

R Development Core Team (2014) R: A Language and Environment for Statistical Computing. R Foundation for Statistical Computing, Vienna, Austria.

Rosen, T. (2012) Analyzing Gaps and Options for Enhancing Argali Conservation in Central Asia within the Context of the Convention on the Conservation of Migratory Species of Wild Animals. Convention on Migratory Species, Bonn, Germany.

Royle, J.A., Chandler, R.B., Sollman, R. \& Gardner, B. (2014) Spatial Capture-Recapture. Academic Press, New York, USA.

Royle, J.A., Magoun, A.J., Gardner, B., Valkenburg, P. \& LowelL, R.E. (2011) Density estimation in a wolverine population using spatial capture-recapture models. The Journal of Wildlife Management, 75, 604-611.

Schaller, G.B. (1972) The Serengeti Lion: A Study of Predator-Prey Relations. University of Chicago Press, Chicago, USA.

Schaller, G.B. (2005) A Winter Survey of Marco Polo Sheep in the Southern Pamir Mountains of Tajikistan. Unpublished report. Wildlife Conservation Society and National Geographic Society, New York, USA.

Schaller, G.B. \& Kang, A. (2008) Status of Marco Polo sheep Ovis ammon polii in China and adjacent countries: conservation of a Vulnerable subspecies. Oryx, 42, 100-106.

Shehzad, W., McCarthy, T.M., Pompanon, F., Purevjav, L., Coissac, E., Riaz, T. \& Taberlet, P. (2012) Prey preference of snow leopard (Panthera uncia) in South Gobi, Mongolia. PLoS ONE, 7(2), e32104.

\section{Biographical sketches}

SHANNON KACHEL's research focuses on behavioural ecology, conservation and non-invasive study of terrestrial carnivores. KYLE MC CARTHY leads research into global felid conservation, development of novel wildlife research technologies, and wildlife behavioural responses to human activities. THOMAS MCCARTHY has worked for over 20 years towards the goal of snow leopard conservation. NUZAR OSHURMAMAdov works on ungulate conservation throughout Tajikistan, focusing on the status of ibex populations in the region. 